\title{
РОЛЬ ВАРИАЦИЙ ГИДРОГЕОЛОГИЧЕСКИХ И СЕЗОННЫХ УСЛОВИЙ НА ИЗМЕНЕНИЕ ХАРАКТЕРИСТИК СЕЙСМИЧЕСКИХ КОЛЕБАНИЙ ВБЛИЗИ КУНГУРСКОЙ ЛЕДЯНОЙ ПЕЩЕРЫ
}

\author{
А.В. ВЕРХОЛАНЦЕВ \\ Горный институт УрО РАН, г. Пермь
}

\begin{abstract}
Аннотация. Как показали выполненные ранее исследования, значительное влияние на усиление амплитуды сейсмических колебаний могут оказывать грунтовые условия. Кроме физико-механических характеристик грунтов, на амплитуду и частотный состав приходящей сейсмической волны оказывают влияние также гидрогеологические факторы. Известно, что уровень грунтовых вод может меняться в зависимости от времени года, а в холодное время года грунты могут промерзать на определенную глубину. Для изучения роли вариации гидрогеологических (УГВ) и сезонных (промерзание грунта) условий в течении года проводились ежемесячные наблюдения методом регистрации взрывов, способом Накамуры, а также методом SASW. В данной статье приводятся результаты данных наблюдений.

Ключевые слова: интенсивность сейсмических воздействий, сейсмическое воздействие, грунтовые условия, резонансы, землетрясение, взрыв, глубина промерзания грунта, уровень грунтовых вод.
\end{abstract}

Введение. Изменение интенсивности сейсмических колебаний на земной поверхности от природных (землетрясение) и техногенных (массовый взрыв) источников обусловлено, в том числе, гидрогеологическими условиями, в частности, глубиной залегания грунтовых вод (уровень грунтовых вод - УГВ), степенью влажности самих грунтов и мощностью водонасыщенной толщи [3]. Известно, что положение УГВ на конкретном участке может изменяться в зависимости от времени года. Более того, на спектральные (резонансные) характеристики может также оказывать влияние глубина промерзания грунта.

Для более детального изучения возможного изменения интенсивности сейсмических колебаний на земной поверхности, которые обусловлены вариациями гидрогеологических (УГВ) и сезонных условий (промерзание грунта), был поставлена и реализована следующая серия экспериментов.

Методы и подходы. На участке с изменяющимся УГВ в течение года (для изучения влияния сезонных условий) проведена серия наблюдений методом регистрации взрывов (один из методов сейсмического микрорайонирования - СМР), способом Накамуры (метод HVSR), а также методом SASW (Spectral Analysis of Surface Waves - Спектральный Анализ Поверхностных Волн).

Тестовый полигон, расположение которого представлено на рис. 1, находился вблизи Кунгурской ледяной пещеры (Пермский край, Кунгурский район).

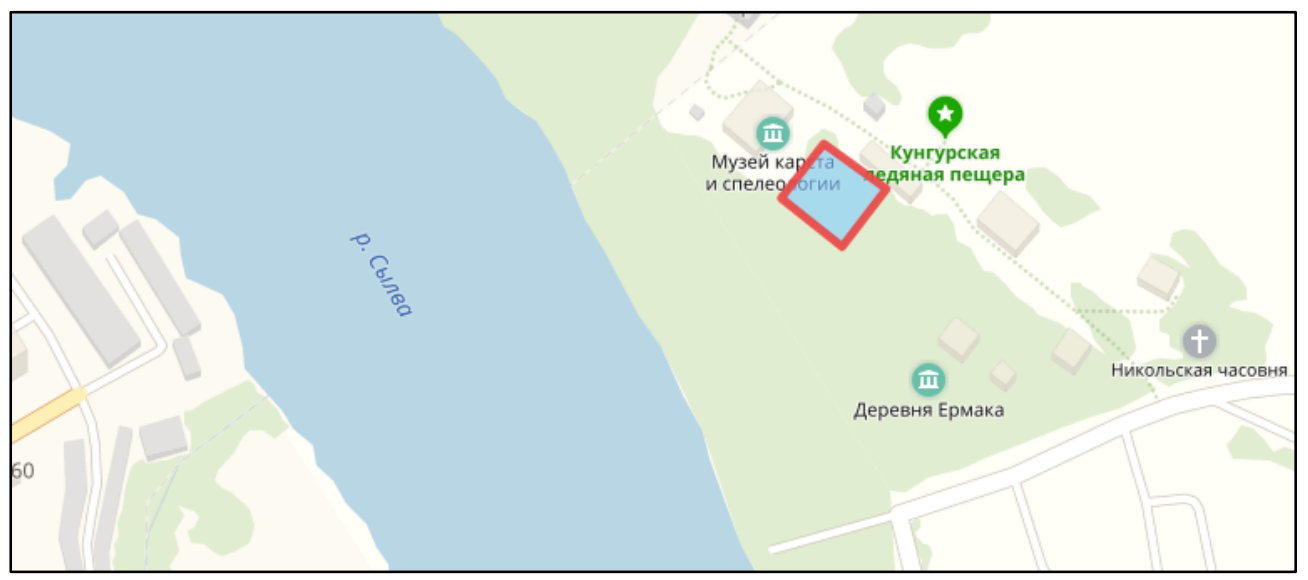

Рис. 1. Расположение тестового полигона (красный прямоугольник) 
Свойства грунтов (рис. 2) известны благодаря бурению разведочных скважин в непосредственной близости от тестового полигона. Информация об уровне грунтовых вод регулярно фиксируются в составе мониторинговых работ, проводимых в пещере сотрудниками Кунгурской лаборатории - стационара. При среднем УГВ 8 м диапазон изменения в течении года не превышает $1.5 \mathrm{M}$.

Для реализации серии экспериментов использовались данные как временно установленной, так и стационарной сейсмической станции регионального значения “Кунгур”. Временная сейсмическая станция была установлена на период проведения экспериментов на территории тестового полигона (исследуемый грунт), тогда как станция “Кунгур" располагается на скальных грунтах непосредственно в пещере (грунты I категории по сейсмическим свойствам). Также была реализована серия ежемесячных (режимных) измерений на территории тестового полигона для изучения характера изменения скоростного разреза методом $S A S W$.

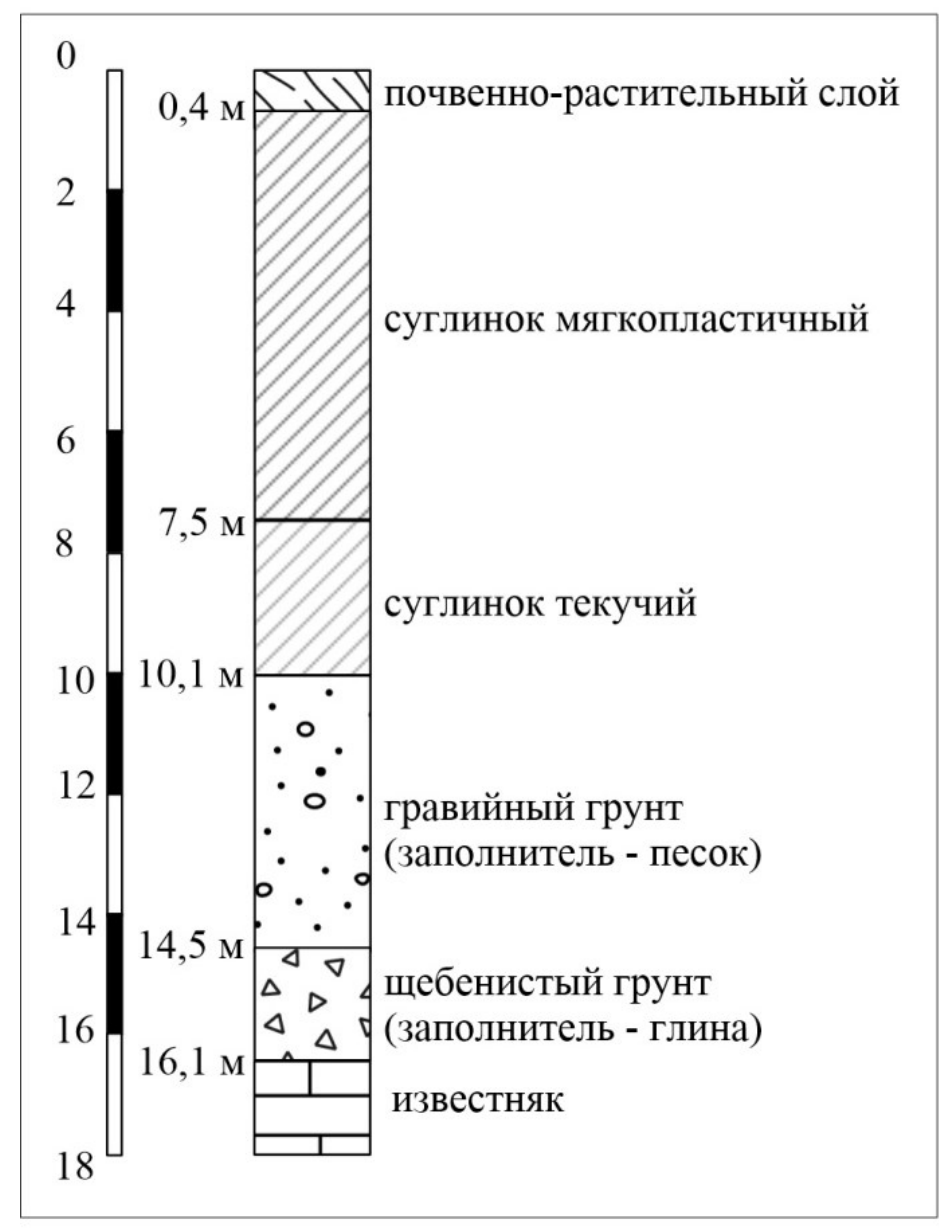

Рис. 2. Изучаемый интервал разреза

Результаты. Взрывные работы, проводимые на карьере строительного камня, расположенного в 20 км от тестового полигона, позволили оценить разницу в отклике отличных по свойствам грунтов на сейсмическое воздействие, а также реализовать метод регистрации взрывов. На рис. 3 представлен амплитудный спектр сейсмического сигнала взрыва, зарегистрированного обеими станциями. Из рисунка можно сделать вывод о значительном влиянии рассматриваемых грунтовых условий: разница зарегистрированных амплитуд достигает более порядка. 


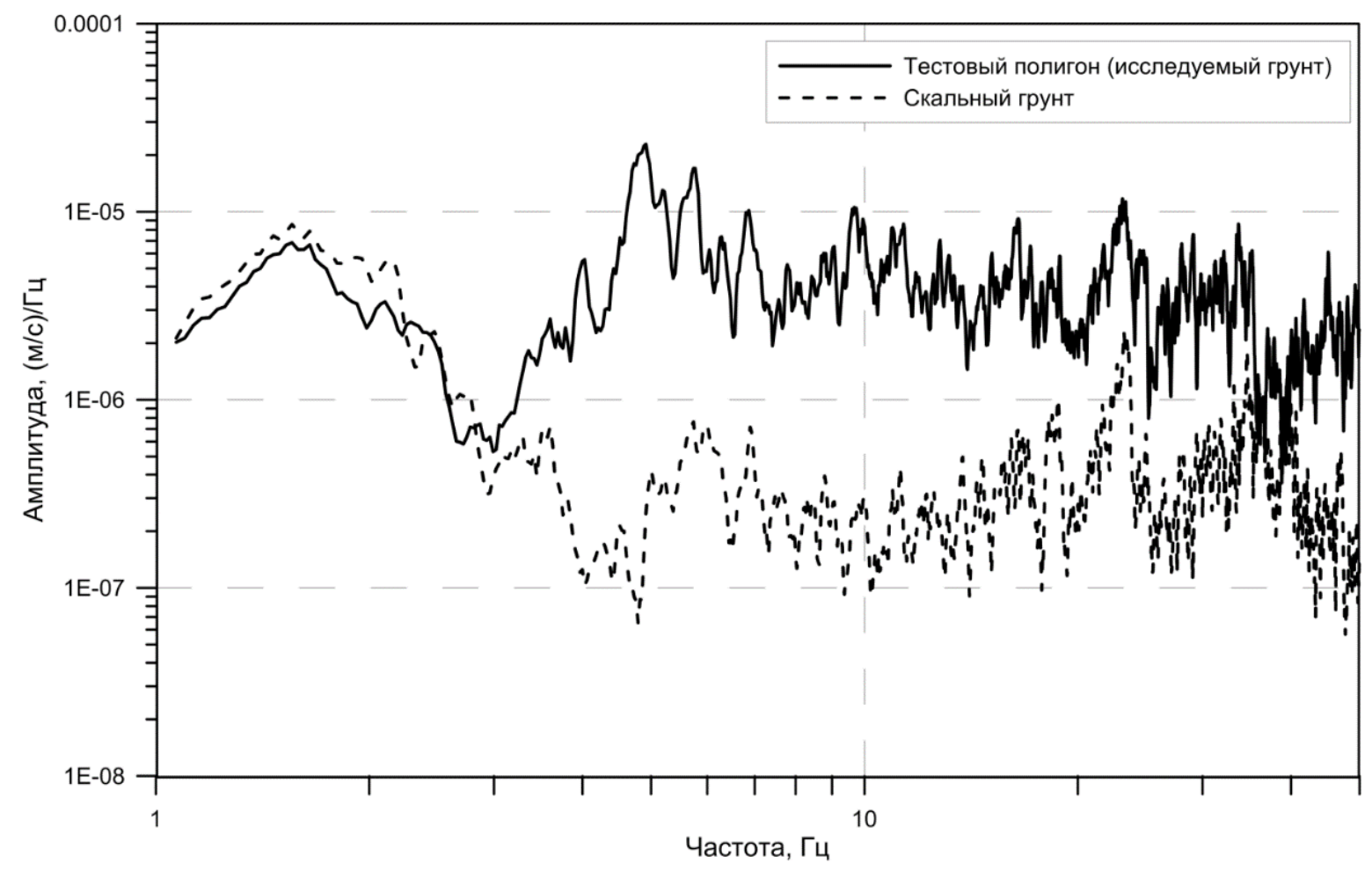

Рис. 3. Амплитудные спектры горизонтальной компоненты зарегистрированного взрыва (эпицентральное расстояние 20 км)

Поскольку частота выполняемых на данном карьере взрывных работ низкая, не удалось выполнить оценку изменения спектральных свойств грунтов в зависимости от времени года (сезонных условий). Однако оценка усилений, полученная по зарегистрированному взрыву, позволяет говорить о наличии резонанса на частоте 5 Гц (рис. 3).

Использование трехкомпонентного сейсмоприемника на временной станции позволило получить резонансные характеристики способом Накамуры (метод HVSR). Изменение поляризационных спектров на исследуемом грунте представлено на рис. 4. Необходимо отметить, что величина усиления, полученная способом Накамуры, претерпевает существенные изменения в зависимости от времени наблюдений. Вместе с этим, общая форма спектров изменяется незначительно, частота резонансной гармоники постоянна и совпадает с частотой, полученной методом регистрации взрывов.

Величина максимального усиления колебаний (на частоте 5 Гц) изменяется от 6.5 до 9. При этом явной зависимости от сезонных условий выявлено не было. Интегральная величина усилений в диапазоне 1-10 Гц составляет от 2.4 до 3.8.

Кроме описанных выше подходов, в рамках экспериментальных исследований были реализованы измерения методом $S A S W$, основанные на частотно-скоростной дисперсии поверхностных волн [8,9]. Измерения проводились как в активном (профиль с расстоянием между сейсмоприемниками 5 м), так и в пассивном режиме (пространственная расстановка с радиусом 15 и 30 м). Данные геологоразведочного бурения позволили достоверно выполнить инверсию полученных дисперсионных кривых в скоростной разрез поперечных волн. Скоростной разрез, в свою очередь, послужил основой для аналитического расчета спектральный характеристик грунтов (с помощью пакета DeepSoil 6.0 [5]). Представленная на рис. 4 кривая резонансных усилений, соответствующая полученному скоростному разрезу поперечных волн, говорит также о наличие максимума на частоте 5 Гц. При этом величина максимального усиления достигает 4.9. 


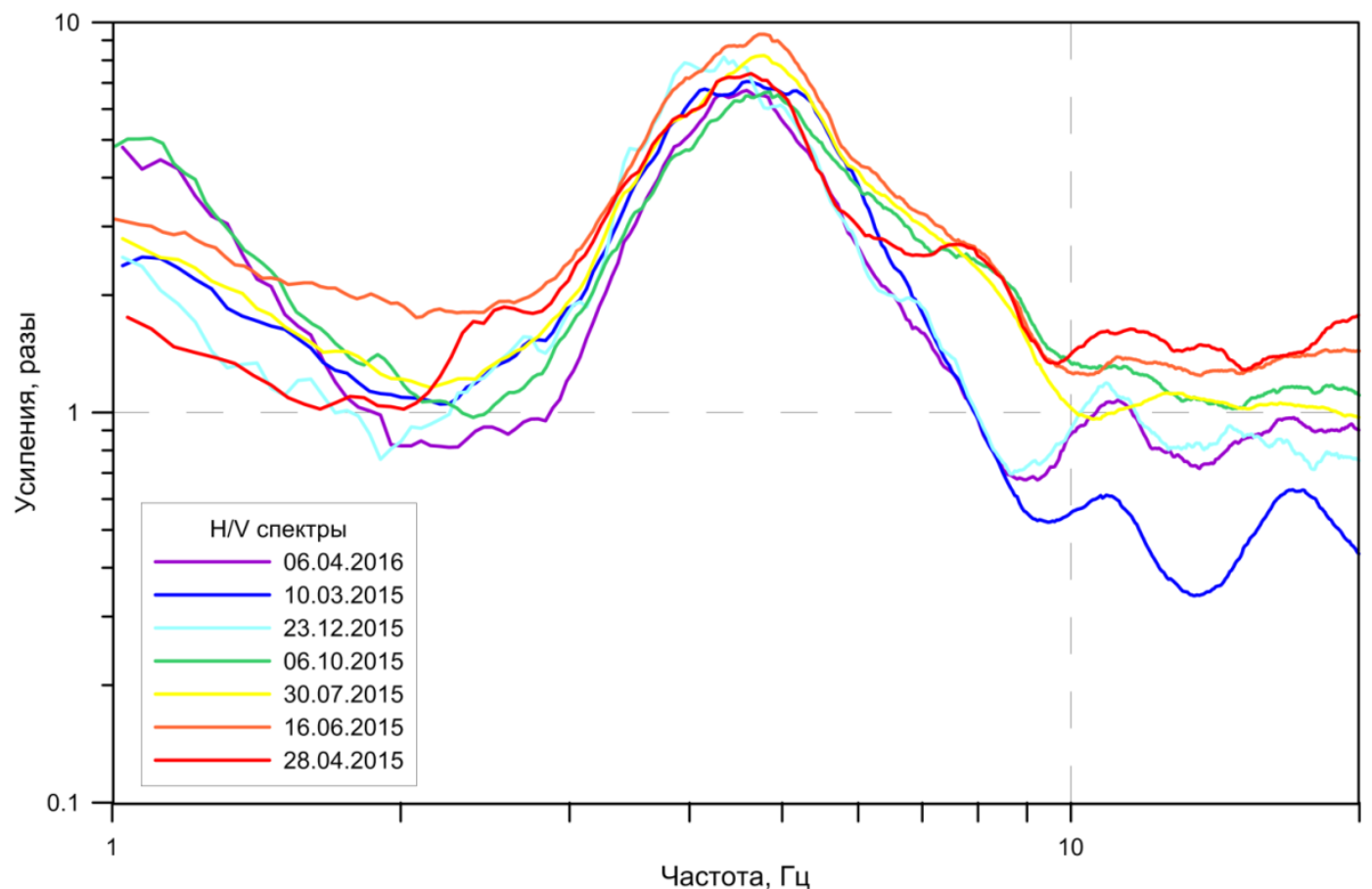

Рис. 4. Поляризационные спектры микросейсмического шума, полученные способом Накамуры (метод HVSR)
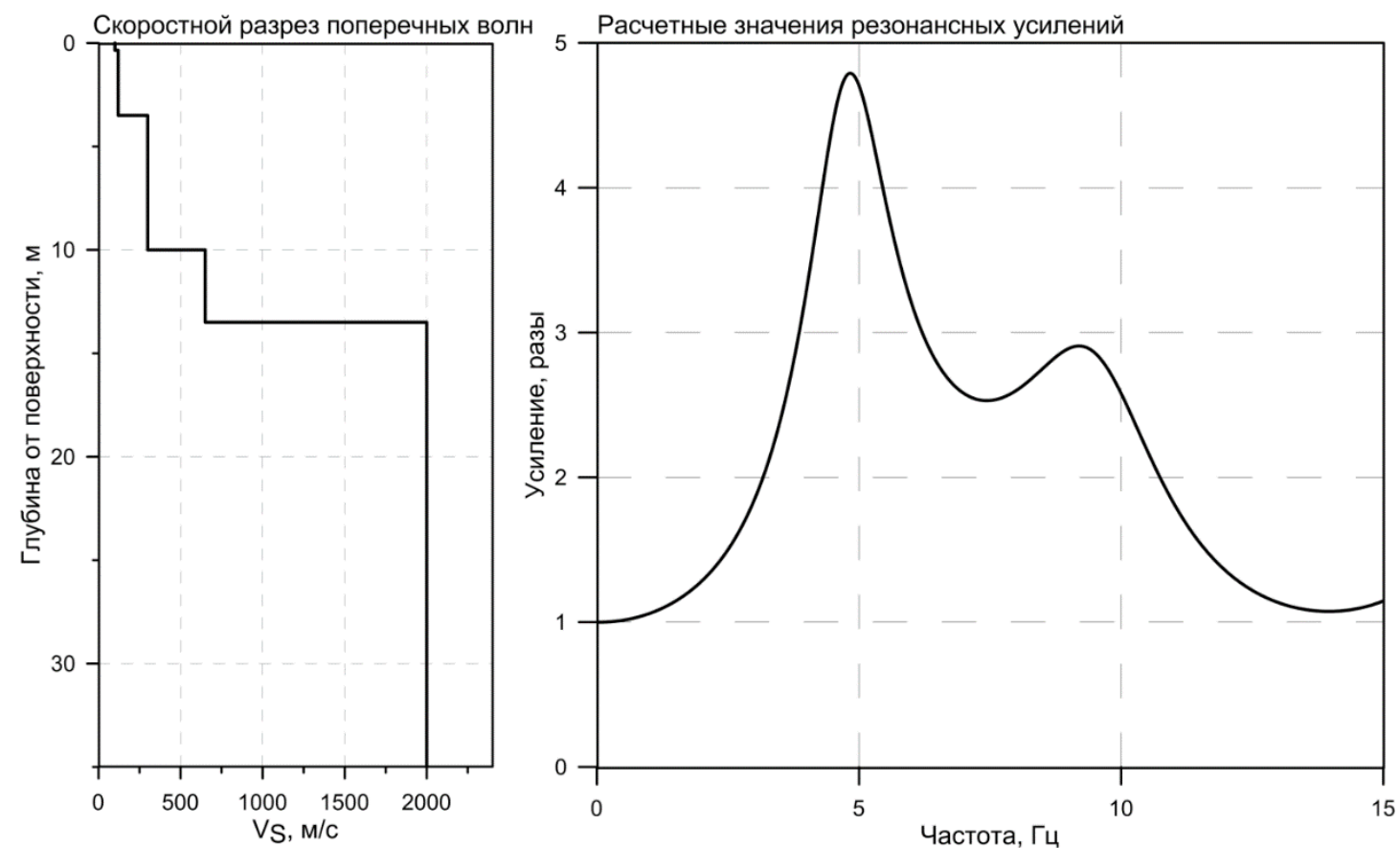

Рис. 5. Скоростной разрез поперечных волн и соответствующие ему резонансные характеристики

Инверсия дисперсионной кривой в скоростной разрез является обратной задачей, точность которой зависит от входных данных (априорной информации). Неоднозначность решения обратной задачи в ходе обработки данных метода $S A S W$ затрудняла сравнение с результатами, полученными методом регистрации взрывов и способом Накамуры. В то же время, сами по себе дисперсионные кривые, характеризующие связь частоты волны с ее скоростью, как показала практика [1] рассчитываются однозначно. В связи с этим было решено использовать для последующего анализа именно их. В итоге, физико-механические свойства грунтов в совокупности со сведениями о скоростном строении стали основой для расчетов методом сейсмических жесткостей $(\mathrm{PCH}$ 
60-86). Так, средняя скорость поверхностной волны $V_{R}$ в 10 -метровой толще (согласно РCH 60-86 учитывается только верхняя толща мощностью 10 м от планировочной отметки) может быть оценена на основании скорости волны длиной 30 м, поскольку глубина проникновения поверхностной волны примерно равна 1/3 ее длины. Средняя скорость поперечных волн $V_{S}$ в 10 -метровой толще в этом случае может быть определена с использованием следующей формулы [2]:

$$
\frac{V_{R}}{V_{S}}=\frac{0.862+1.14 \mu}{1+\mu},
$$

где $\mu$ - коэффициент Пуассона. Далее отношения сейсмических жесткостей на исследуемом и эталонном грунте (в пещере) будут характеризовать усиления колебаний. В таблице 1 представлены расчеты методом сейсмических жесткостей (МСЖ) усилений грунтами для разных длин волн ( $\lambda$ ), полученных в ходе серии экспериментов в течение года. Можно отметить, что максимальные значения усилений (как и ожидалось) наблюдаются в весенне-летний период. При этом минимальными усилениями характеризуются исследуемые грунты в зимний период, когда УГВ понижается. Вместе с этим разброс значений не превышает $10 \%$, что говорит о незначительном влиянии сезонных изменений на интегральное усиление за счет грунтов.

Усиления сигнала за счет грунтов (разы), рассчитанные по сейсмическим волнам разной длины

\begin{tabular}{|c|c|c|c|c|}
\hline $\begin{array}{c}\text { Дата исследова- } \\
\text { ния }\end{array}$ & $\begin{array}{c}\lambda=50 \\
\mathrm{M}\end{array}$ & $\begin{array}{c}\lambda=40 \\
\mathrm{M}\end{array}$ & $\begin{array}{c}\lambda=30 \\
\mathrm{M}\end{array}$ & $\begin{array}{c}\lambda=20 \\
\mathrm{M}\end{array}$ \\
\hline 24.04 .2015 & 1.17 & 1.26 & 1.38 & 1.55 \\
\hline 21.05 .2015 & 1.19 & 1.28 & 1.39 & 1.57 \\
\hline 23.06 .2015 & 1.18 & 1.27 & 1.38 & 1.54 \\
\hline 30.07 .2015 & 1.21 & 1.29 & 1.41 & 1.57 \\
\hline 08.09 .2015 & 1.20 & 1.29 & 1.40 & 1.54 \\
\hline 06.10 .2015 & 1.21 & 1.29 & 1.39 & 1.52 \\
\hline 12.11 .2015 & 1.20 & 1.29 & 1.40 & 1.56 \\
\hline 23.12 .2015 & 1.16 & 1.24 & 1.36 & 1.54 \\
\hline 04.02 .2016 & 1.12 & 1.21 & 1.34 & 1.53 \\
\hline 02.03 .2016 & 1.12 & 1.22 & 1.34 & 1.54 \\
\hline 06.04 .2016 & 1.14 & 1.24 & 1.37 & 1.56 \\
\hline
\end{tabular}

Выводы. Кривые резонансных усилений, полученные разными способами, свидетельствуют о наличии максимумов на одной и той же частоте, что говорит, о корректности используемых подходов. Несмотря на то, что величина максимального усиления, полученная способом Накамуры, в течении года изменяется от 6.5 до 9, явной зависимости от сезонных условий выявлено не было. Применен ранее протестированный подход [1] оценки усиления сигнала за счет грунтов, заключающийся в использовании средней скорости поверхностных волн (рассчитанной через дисперсионную кривую) для расчета методом МСЖ. Результаты расчета методом МСЖ свидетельствуют о слабой зависимости усилений (не больше 10\%) от сезонных вариации УГВ. 


\title{
БИБЛИОГРАФИЧЕСКИЙ СПИСОК
}

1. Верхоланцев А.В. Использование дисперсионных кривых поверхностных волн для изучения грунтовых условий в рамках работ по СМР // Современные методы обработки и интерпретации сейсмологических данных: материалы ХІІ Междунар. сейсмологич. шк. / ФИЦ «ЕГС РАН». - Обнинск, 2017. - С. 79-81.

2. Викторов И.А. Физические основы применения ультразвуковых волн Рэлея и Лэмба в технике. - М.: Наука, 1966. - 168 с.: ил.

3. Ершов И.А., Попова Е.В. О влиянии обводненности грунтов на интенсивность сейсмического воздействия // Эпицентральная зона землетрясений. - М.: Наука, 1978. - С. 117-140. - (Вопросы инженерной сейсмологии. Вып.19.).

4. РСН 60-86. Инженерные изыскания для строительства. Сейсмическое микрорайонирование. Нормы производства работ. - Введ. 1987-01-01. - М., 1997. - 17 с.

5. DEEPSOIL V5.1: User Manual and Tutorial / Hashash Y.M.A. - 2012. - 107 p. - Текст электронный // URL: https://pdfslide.net/documents/user-manual-and-tutorial.html (Дата обращения 25.11.2019)

6. Nakamura Y. A method for dynamic characteristics estimation of subsurface using microtremor on the ground // Quarterly Report of RTRI. - 1989. - V. 30, № 1. - P. 25-33.

7. Verkholantsev A.V., Shulakov D.Y., Dyagilev R.A. Features of assessing seismic effects of blasting operations // Gornyi Zhurnal. - 2019. - № 5. - P. 29-36. DOI: 10.17580/gzh.2019.05.05.

8. Nazarian S., Stokoe K.H. In situ shear wave velocities from Spectral Analysis of Surface Waves // Proceedings of the eighth World Conference on Earthquake Engineering, july 21-28, 1984. San Francisco California U.S.A. - New Jersey, 1984. - V. III. - P. 31-38.

9. Xia J., Miller R.D., Park C.B. Estimation of near-surface shear-wave velocity by inversion of Rayleigh waves // Geophysics. - 1999. - V. 64, № 3. - P. 691-700.

\section{ОПЕРАТИВНЫЙ ПРОГНОЗ ИЗМЕНЧИВОСТИ ФИЗИКО-МЕХАНИЧЕСКИХ СВОЙСТВ ПРОДУКТИВНЫХ ПЛАСТОВ ПО ДАННЫМ ШАХТНЫХ СЕЙСМОАКУСТИЧЕСКИХ ИССЛЕДОВАНИЙ}

\author{
А.И. БАБКИН \\ Горный институт УрО РАН, г. Пермь
}

\begin{abstract}
Аннотация: Регламентируемые для калийных рудников Верхнекамского месторождения солей геомеханические расчёты устойчивости подземных конструкций базируются на нахождении деформационных показателей по образцам горных пород. Дискретность отбора образцов для прочностных испытаний не позволяет учесть значимые локальные изменения важных механических показателей. В статье представлены результаты шахтных многоволновых сейсмоакустических исследований, проводимых с целью нахождения прогнозных оценок изменчивости физико-механических свойств продуктивных пластов калийных рудников вдоль выработок. Прогноз строится на статистической обработке полученных сейсмоакустических данных совместно с результатами лабораторных испытаний образцов горных пород на прочностные свойства.
\end{abstract}

Ключевые слова: шахтные многоволновые сейсмоакустические исследования, прогноз физикомеханических свойств горных пород, определение прочностных показателей калийно-магниевых солей.

Согласно Указаниям по защите рудников от затопления и охране подрабатываемых объектов на Верхнекамском месторождении калийно-магниевых солей [1] производятся геомеханические расчёты параметров систем разработки рудного тела. В качестве параметрического обеспечения геомеханических расчётов устойчивости подземных конструкций наиболее часто используют деформационные показатели, определенные статическим методом при испытании образцов под нагрузкой. Из них наиболее значимыми является определение прочности при сжатии. Принятая сетка отбора проб (порядка 200 метров) позволяет оценить особенности изменения $\sigma_{\text {Сж и }}$ других параметров для отдельных разрабатываемых панелях. Учитывая малые размеры возможных геологических неоднородностей в разрезе и их влияние на проч- 